\title{
Design and Empirical Study of an Online Education Platform Based on B2B2C, Focusing on the Perspective of Art Education
}

\author{
Shaopeng Hou ${ }^{1}$, Jongchang Ahn ${ }^{2 *}$ \\ ${ }^{1}$ Department of Information Systems, Hanyang University \\ Seoul, 04760 Republic of Korea \\ [e-mail: hsp931212@hanyang.ac.kr] \\ 2 Department of Information Systems, Hanyang University \\ Seoul, 04760 Republic of Korea \\ [e-mail: ajchang@hanyang.ac.kr] \\ ${ }^{*}$ Corresponding author: Jongchang Ahn
}

Received September 2, 2021; revised October 18, 2021; accepted November 21, 2021; published February 28, 2022

\begin{abstract}
The purpose of this study is to provide instructive theoretical models for art (music) education institutions especially when unpredictable risks, such as pandemics, occur again. Based on the customer behavior theory of the business-to-business-to-customer (B2B2C) platform, and in combination with the technology acceptance model (TAM) and expectation confirmation model (ECM), this study proposes an online education model from the perspective of art education. The framework is based on the three decision-making processes of the customer, and includes the product owner, content owner, and customer area. This paper highlights the factors that influence customers in making decisions when art education institutions are product owners. Regression analysis was introduced to study the factors influencing the expectation confirmation, and the overall fitting testing and six hypotheses testing of 385 effective samples were performed using the structural equation modeling (SEM). The results show that the course-design and after-service positively influenced the expectation confirmation, and the domain image positively influenced the continuance behavior. Negative emotions skipped the mediator (expectation confirmation) and directly exerted a significant negative impact on customers' willingness to continue system usage (continuance behavior). In addition, expectation confirmation positively influenced continuance behavior. The paths of detailed items comprising course-design, after-service, and negative emotion were also analyzed and discussed. In this path analysis, ordinary art learners did not believe that AI
\end{abstract}

A preliminary version of this paper appeared in 2021 The $16^{\text {th }}$ Asia Pacific International Conference on Information Science and Technology (APIC-IST 2021), June 20-22, Busan, Republic of Korea. This version includes the detailed framework of B2B2C model and SEM path analysis results. We express our thanks to the conference committee for selected this as an outstanding paper. 
partners can play a very good auxiliary role. The findings contribute to the scope of information systems acting as an art education platform academically, and provide effective and theoretical support for the actual operation of art education institutions.

Keywords: After services, art education, B2B2C, course design, education model, influencing factor

\section{Introduction}

As information technology rapidly develops, the diversified internet environment is constantly changing people's lives and learning habits. It is difficult for art (e.g. music) education institutions, as traditional physical enterprises, to conduct transformations in online education due to the particularity of learning art. However, according to the data research report acquired from iiMedia.cn, the number of online education users in China reached 259 million in 2019, and it is predicted to reach 446 million in 2021 [1]. Considering the huge demand of users, there is an urgent requirement for the art education industry to perform transformations.

The COVID-19 pandemic, running rampant since the beginning of 2020, posed a major risk for all physical enterprises [2]. Particularly, art education institutions, which are primarily conduct face-to-face teaching, are experiencing difficulties in business. Small-and mediumsized institutions lost the support of cash flow and had to be shut down. According to the China Musical Instrument Association (CMIA), although the pandemic has caused great difficulties in the operation of enterprises, it will also become a new opportunity for the art education industry [3].

The classic model of online education is subject to Massive open online course (MOOC). These types of open online education courses have attracted wide attention in the early stage of promotion because of its advantages, such as wide coverage of content and free learning mode. However, after a period of development, problems such as poor user engagement, mismatch between user demands and courses, and low learning initiatives gradually emerge $[4,5]$. Therefore, it is necessary to have a deeper understanding of the actual necessities and behavior characteristics of online learning users to break through the bottleneck of industry development. In this paper, an operation model based on the business-to-business-to-customer (B2B2C) mode is proposed from the perspective of art (music) education, and potential factors that affect user experience are determined through statistical empirical analysis. In addition, reasonable optimization suggestions for art education enterprises are proposed.

The remainder of this paper is organized as follows. Section 2 reviews previous literature on user behavior and online education platforms. Section 3 discusses the development of a research model on B2B2C, and the required hypotheses are set to test significant paths. In Section 4, a sample is analyzed using statistical methods, including structural equation modeling (SEM), for the research model. Section 5 discusses the findings and provides several suggestions. Finally, Section 6 concludes the research and presents the limitations and directions for further study. 


\section{Literature Review}

\subsection{User Behavior Research}

Davis (1989) proposed a theoretical model, namely the technology acceptance model (TAM), to study users' acceptance of information systems (ISs) [6]. This effectiveness of this model has also been reported [7]. Adwan used a basic TAM for the first time to study the willingness of students at the University of Jordan to adopt e-learning, and the results indicated that TAM can explain the usage behavior of online learning users appropriately [8]. Hueros integrated 'technical support' and 'computer efficiency' into TAM as external variables to study students' willingness to accept the learning management WebCT [9]. To investigate the acceptance of Open Delos, which is an online open course platform for Greek users, Apostolidis et al. (2015) added the external variable 'network experience' to the TAM model. An analysis of the hypothetical path of the model revealed that optimizing the network quality is vital to improve the experience of online courses [10]. Oliver (1980) first proposed the expectationconfirmation theory (ECM) to study product reconsumption and service renewal [11]. Lee (2010) first integrated the variables of ECM in TAM, proving that the classic TAM is very effective when used together with ECM in different fields [12].

\subsection{Online Education Platform}

The traditional online education platform originated from the MOOC model, and was created by several top universities in the US [5]. This model has received extensive attention owing to the rich knowledge types and characteristics of fully open teaching. However, this model features a high threshold and requires institutions to develop courses independently [13]. For small-and medium-sized art education institutions, maintaining a stable cash flow under risks is challenging, let alone make investments to develop open courses. Therefore, commercial online education platforms have gradually emerged. Education platforms in China can be divided into content-based, tool-based, platform-based, and comprehensive platforms according to different service types. The platforms can also be categorized according to different business modes, including business to business (B2B), business to customer (B2C), B2B2C, customer to customer (C2C), and customer to business (C2B), [14]—of which B2B, $\mathrm{B} 2 \mathrm{C}$, and B2B2C modes all consider the enterprise as the starting point of service. However, because the implementation of art courses from the perspective of art education requires the active cooperation of the platform owner, only the B2B2C model can achieve this effect well.

In general, B2B2C is an electronic business model that is dependent on the internet. The first B represents the product owner, which primarily serves the functions of provision of products, goods inventory, and production and transportation within the mode. The second B represents the platform owner, which primarily serves the functions of resource integration, technical support, information feedback, and mutual guarantee within the mode. C represents the customer, which is not limited to the enterprise and collective. Individual buyers can also identify the products and services required in this model [15]. With the advancement of business modes, online education, internet finance, and online auctions have been gradually incorporated in the B2B2C model, and thus it is no longer limited to the e-commerce field [16].

MOOC platforms still dominate current research on online education platforms. To further explore the impact of perceptual interaction on online learners' willingness to continue learning, Zhao et al. (2018) applied the "stimulus-organism-response" (S-O-R) model in their study [4]. Alraimi et al. (2015) introduced the three variables of perceived openness, perceived reputation, and perceived interest into the ECM-IS model, and applied the integrated model to 
research the continued usage behavior of MOOC users. The empirical results show that "perceived openness" and "perceived interest" are two influencing factors that influence users' willingness of continued usage behavior [5]. He (2019) suggests that customer behavior can be divided into three stages, namely recognition, trial, and service, on online education platforms based on the B2B2C model [17]. The suggestion can be expanded and utilized in an operation model applicable to art education institutions based on the proposed three stages [17].

\section{Research Model Design}

The purpose of this study is to improve the operation mode of traditional art education institutions and propose a rational transformation mode of enterprises, considering social risks such as pandemics. Therefore, this section begins with an analysis of the operation mode of traditional education institutions, and explains the existing defects and risks. Combined with the B2B2C platform, a new operation model suitable for art education institutions is proposed.

\subsection{Traditional Offline Operation Model}

In China, art education institutions with a social nature have emerged as the fundamental carriers of art resources in life. Because of the special nature of art education that requires teaching by an example, the form of operation has remained unchanged during long-term commercial development. Traditional art education institutions primarily profit from course fees and musical instrument sales [18]. This paper proposes an online education model; therefore, there is no detailed explanation of musical instrument sales. Course fees are mainly derived from offline enrollment. Fig. 1 demonstrates the specific enrollment process $[18,19]$.

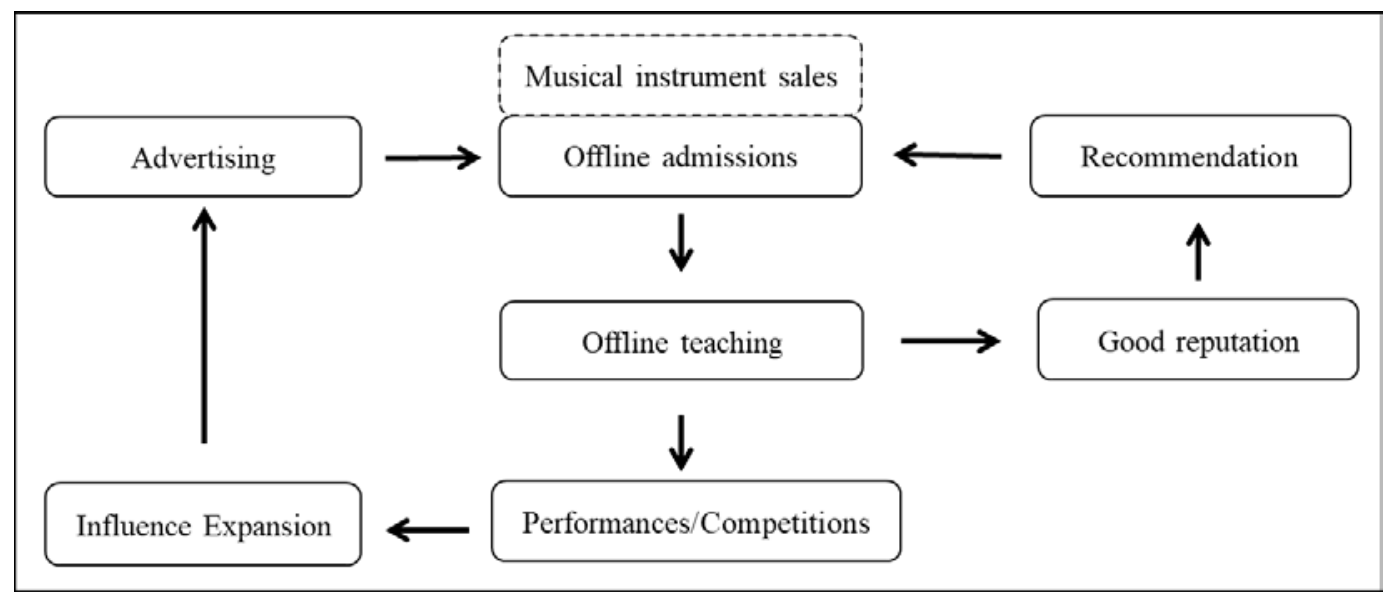

Fig. 1. Operation flow chart of traditional art education institutions 
Students register for courses based on advertisements by educational institutions and promotions among customer communities. After enrolling sufficient students, the courses will be reasonably arranged in accordance with the learning demands of the students. In the process of continuous offline learning, a good reputation can be accumulated, and community effects are generated to enroll new students [19]. Accordingly, the first closed loop in the traditional operation mode is formed. Art education institutions also raise their local awareness by organizing performances or competitions. These types of events tend to attract many students or parents interested in arts, thus achieving a wider advertising effect. Usually, this practice exerts a large and effective impact on educational institutions [19], thereby forming the second closed loop in the traditional model.

The traditional operation mode has the following defects and risks: 1) Singularity: Offline education is the core part of the entire model. However, against the backdrop of certain risks, such as pandemics, and when normal offline education cannot be conducted, neither of the original two closed loops of this mode can be realized. Consequently, small-and medium-sized enterprises that rely on cash flow cannot operate normally. 2) Insufficient resources: Traditional education institutions have a small scope of influence; therefore, the resources of students and teachers can only be expanded locally. It is difficult for enterprises to expand their scale, and they cannot make greater progress in the information age. 3) Outdated teaching format: Art education institutions are important training places for non-professional art talent. The traditional teaching model cannot add more interesting elements, and repeated training makes this type of teaching often boring [18]. It is more difficult for beginners to persevere when studying for a long time. Therefore, the loss of students is also a risk factor in the traditional model.

\subsection{New Model-Based on B2B2C}

The B2B2C model is characterized by a customer-centered cooperation between the platform owner and product owner to achieve win-win results. The continued use of the IS refers to the user's willingness or behavior to continue using the system for a long time after the initial adoption [20]. A research report [17] indicated that customers on the B2B2C platform had three decision-making behaviors in the process of continued use. The decision is accompanied by the loss of customers every time [17]. We consider the education platform as an example. While the platform owner is responsible for building a teaching environment, it also creates social credibility for the product owner. After stationing to the platform, the product owner can upload high-quality teaching content and arrange live courses. Both sides made auxiliary measures at different decision-making stages of the customer to improve customer experience and enhance interest in learning, and ultimately reduce loss of customers for mutual benefit. This study combines the TAM [8] and ECM [12] based on the three decision-making processes of the customer, and proposes a model for art education on the B2B2C platform. The model structure is presented in Fig. 2. 


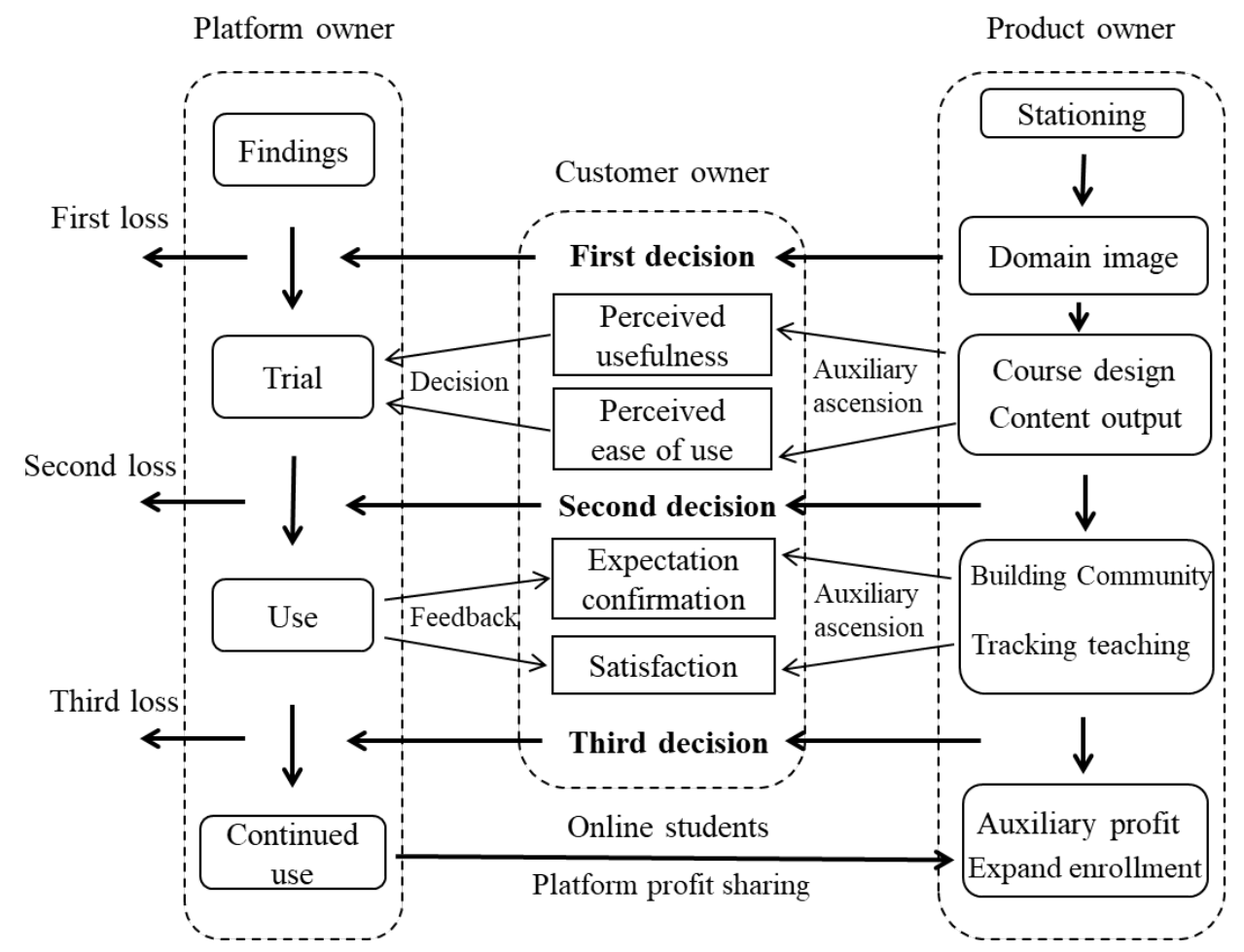

Fig. 2. Music academy operation model based on B2B2C platform

\subsection{Model Interpretation and Research Hypothesis}

The customer makes the first decision after initial use of the platform. According to [21], the credibility and influence of internet business platforms have a significant positive correlation with the establishment of customers' initial impressions. The domain image of the product owner plays a supporting role. When an art education institution acts as a product owner, it should first choose a B2B2C platform with a wide range of promotions, good reputation, and diversified cooperation methods. Large-scale promotions can effectively increase passive customer groups, and a good reputation can help acquire more active customer groups. Diversified cooperation methods not only effectively helps the product owner establish a corporate image, but also delivers more development possibilities in the later stages. The domain image can be displayed by demonstrating the local scale of the education institution, quality of teachers, and performances held. The user behavior of a mobile terminal was studied [22], and it was found that based on the richness of the application interface and information obtained during initial use, the user decides whether to continue using the application. Accordingly, the following hypothesis is proposed:

H1: The domain image will have a significant positive impact on the willingness of continued use.

The second decision is made after users have attempted using the platform and courses. The second choice of users reflects the acceptance of the IS. According to the TAM, perceived usefulness and perceived ease of use are two indicators that dominate the adoption behavior of ISs [6]. He [17] and Hsu and Lin [22] indicated in their research results that the content of courses on online education platforms is the core factor in enhancing customer perception. At 
this stage, art education institutions should improve the course arrangement to control content output. Accordingly, customers decide on the continued use of the course. Based on an investigation, teachers in ordinary small- and medium-sized art education institutions change frequently, leading to unstable education quality. Authoritativeness, learnability, and practicality are shared traits of excellent courses [23]. Other research [24] conducted with MOOC users has demonstrated that the quality of courses and auxiliary materials contribute significantly to promoting customers' perception of learnability and expectation confirmation. Therefore, from the perspective of art education, the impact of course design will be measured in terms of professionalism, difficulty, diversity, and practicality. Therefore, the following hypothesis is proposed:

H2: Course design will have a significant positive impact on expectation confirmation.

Customers make a third decision after a period of formal use. In contrast to the previous two stages, customers at this stage have already accumulated a certain understanding and preliminary recognition of the platform and product owners. Customers at this stage are likely to spend more time experiencing functions and services that they did not know during the trial stage [17]. In the B2B2C education platform, customers at this stage will evaluate their learning results after use, which is directly fed back into the expectation confirmation. Therefore, the product owner at this stage can further improve customer satisfaction with individual tutoring. With the development of AI technology, music internet education reaped USD 1.1 billion in funding in 2019 [25]. After-school tutoring that integrates AI technology will also be expected. Real-time communication can be realized in most B2B2C platforms. Research indicates that in art education, multi-person communication among communities will further help students study more, compared to independent learning [26]. Therefore, in the third stage, the impact of after-service on expectation confirmation is verified based on individual tutoring, AI partner, community communication, and examination arrangement. Accordingly, the following hypothesis is proposed:

H3: After-service will have a significant positive impact on expectation confirmation.

Lin et al. (2011) explained the research objectives from three different angles of learning management—system, teaching, and interaction — when studying the negative feedback of online learning and customer satisfaction with learning quality. This research proved that negative feedback has a significant impact on learning satisfaction [27]. According to data from iiMedia Research, people without online learning experience are concerned about not being able to communicate in real time and accomplish their learning goals [28]. The question of how to improve MOOC learners' initiative is worthy of discussion in the field of online learning [13]. Various negative emotions may exist before customers participate in platform courses, and such emotions may affect customers' decisions during their use. Therefore, the aforementioned three aspects (communication, learning goal, and initiative) will be considered to verify the influence of negative emotions on attitudes toward continued use. Accordingly, the following hypothesis is proposed:

H4a: Negative emotions will have a significant negative impact on expectation confirmation.

H4b: Negative emotions will have a significant negative impact on customers' willingness of continued use.

Expectation confirmation refers to a comparison between customers' expectations and their practical experiences with ISs. Bhattacherjee (2001) listed expectation confirmation as an important variable in behavioral research on customers' continued use [29]. Many behavioral studies have demonstrated that expectation satisfaction is an excellent mediator 
linking antecedent variables with the willingness to continue use [30,31]. Therefore, the following hypothesis is proposed:

H5: Expectation confirmation has a significant positive impact on customers' willingness to continue use.

Fig. 3 illustrates the final research model diagram.

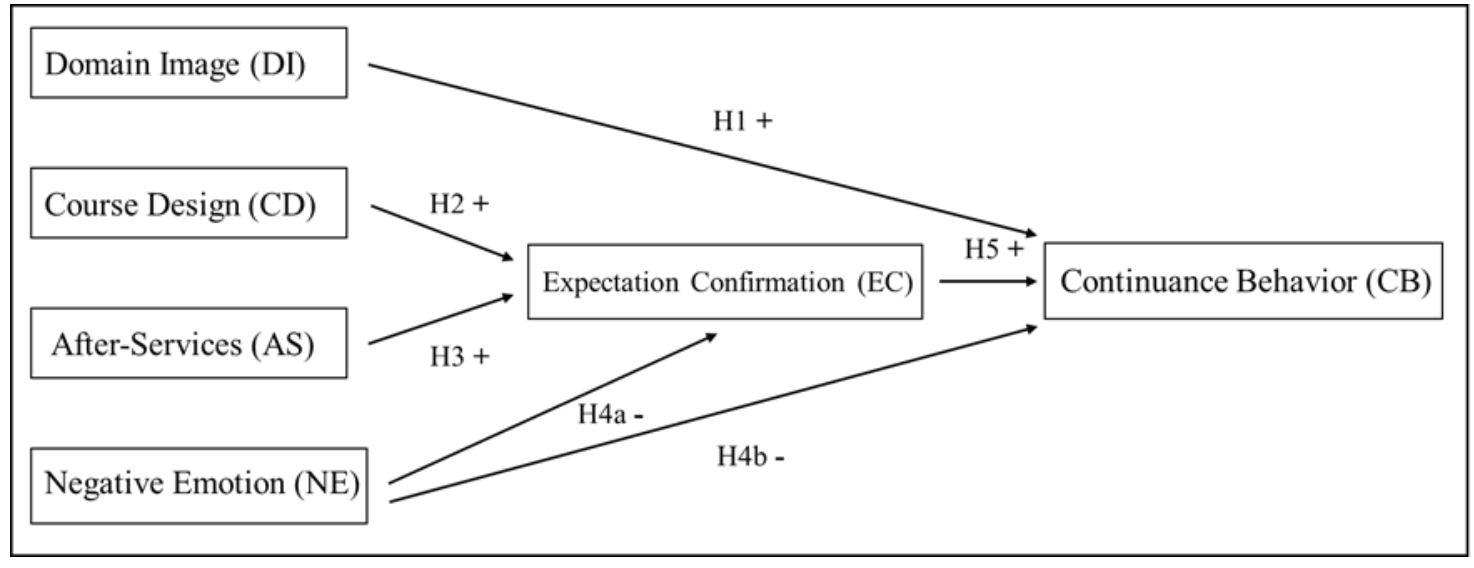

Fig. 3. Research model

\section{Results}

Data were collected using questionnaires. The questionnaire consists of Part A and Part B. Part A is mainly used to collect the demographic characteristics of the survey group; and Part B sets questions based on the six hypotheses and multiple aspects mentioned in the previous explanation. The questions were measured using a Likert scale. Regression and correlation analyses were implemented using IBM SPSS 22 version; and SEM and path analysis were implemented using IBM AMOS.

\subsection{Data Analysis}

Respondents were drawn from 15 offline art education institutions in Jinan, China, and 432 samples were collected. Data was cleaned before the empirical analysis. Samples with identical answers were removed, and the median was used to fill in the vacant values, resulting in 385 valid samples. Among them, we observed that more women preferred learning art than men, with only $36.5 \%$ of respondents. A total of $77.8 \%$ of users were under 30 years old, indicating that young people form the primary group interested in learning art. Meanwhile, $40.8 \%$ of respondents said they had not used an online learning platform, but considered it an appropriate approach towards learning. Additionally, 5.3\% of respondents answered that online learning was not worth promoting.

Reliability analysis was performed to study the reliability of the quantitative data [32]. Table 1 presents the reliability analysis results for the six items in the questionnaire. Each of these items has an $\alpha$ value of approximately 0.8, indicating high item reliability [33]. Each of these items has a factor loading above 0.7 for the core questions, indicating that the variables of the item have a strong independent differentiation-all of which can effectively correspond to the correct latent variables. Table 1 also lists the combined reliability (CR) and average variance extracted (AVE). The AVE and CR of all items exceed 0.5 and 0.7 , respectively. Consequently, a relatively high degree of data aggregation was demonstrated [34-36]. 
Table 1. Values of factor loading, Cronbach's alpha, CR, and AVE

\begin{tabular}{|c|c|c|c|c|c|}
\hline Variables & Questions & $\begin{array}{c}\text { Factor } \\
\text { Loading }\end{array}$ & $\begin{array}{c}\text { Cronbach's } \\
\alpha\end{array}$ & CR & AVE \\
\hline \multirow{2}{*}{ DI } & DI1 & 0.769 & \multirow{2}{*}{0.849} & \multirow{2}{*}{0.747} & \multirow{2}{*}{0.596} \\
\hline & DI2 & 0.776 & & & \\
\hline \multirow{4}{*}{ CD } & CD1 & 0.788 & \multirow{4}{*}{0.793} & \multirow{4}{*}{0.873} & \multirow{4}{*}{0.632} \\
\hline & CD2 & 0.780 & & & \\
\hline & CD3 & 0.801 & & & \\
\hline & CD4 & 0.812 & & & \\
\hline \multirow{4}{*}{ AS } & AS1 & 0.867 & \multirow{4}{*}{0.877} & \multirow{4}{*}{0.904} & \multirow{4}{*}{0.702} \\
\hline & AS2 & 0.817 & & & \\
\hline & AS3 & 0.836 & & & \\
\hline & AS4 & 0.832 & & & \\
\hline \multirow{3}{*}{ NE } & NE1 & 0.827 & \multirow{3}{*}{0.811} & \multirow{3}{*}{0.870} & \multirow{3}{*}{0.627} \\
\hline & NE2 & 0.789 & & & \\
\hline & NE3 & 0.785 & & & \\
\hline \multirow{3}{*}{ EP } & EP1 & 0.858 & \multirow{3}{*}{0.786} & \multirow{3}{*}{0.881} & \multirow{3}{*}{0.712} \\
\hline & EP2 & 0.855 & & & \\
\hline & EP3 & 0.818 & & & \\
\hline \multirow{2}{*}{ CB } & CB1 & 0.734 & \multirow{2}{*}{0.835} & \multirow{2}{*}{0.732} & \multirow{2}{*}{0.578} \\
\hline & CB2 & 0.786 & & & \\
\hline
\end{tabular}

Discriminant validity is calculated by measuring the difference between the square root of the AVE of a variable in the model and the correlation coefficient between that variable and other variables [33]. Table 2 lists the correlations between the variables and square root values of the AVE (bold text). The correlations between items are all less than the square root of the AVE, indicating that the discriminant validity among samples is appropriate.

Table 2. Discriminant validity of constructs

\begin{tabular}{ccccccc}
\hline & DI & CD & AS & NE & EP & CB \\
\hline DI & $\mathbf{0 . 7 7 2}$ & & & & & \\
CD & 0.446 & $\mathbf{0 . 7 9 4}$ & & & & \\
AS & 0.552 & 0.155 & $\mathbf{0 . 8 3 7}$ & & & \\
NE & 0.330 & 0.558 & 0.427 & $\mathbf{0 . 7 9 1}$ & & \\
EP & 0.512 & 0.424 & 0.395 & 0.254 & $\mathbf{0 . 8 4 3}$ & \\
CB & 0.475 & 0.554 & 0.483 & 0.271 & 0.405 & $\mathbf{0 . 7 6 0}$ \\
\hline
\end{tabular}

\subsection{Regression Analysis}

To investigate the internal relationship between the two crucial decisions made by customers in the use process, a regression analysis was conducted on the detailed variables in course design, after-service, and negative emotion. The dependent variable was expectation confirmation. Table 3 presents a summary of the regression analysis. 
Table 3. Model Summary

\begin{tabular}{ccccc}
\hline $\mathbf{R} \quad \mathbf{R}^{2}$ & $\begin{array}{c}\text { Adjusted } \\
\text { R Square }\end{array}$ & $\begin{array}{c}\text { Std. Error of the } \\
\text { Estimate }\end{array}$ & $\begin{array}{c}\text { Durbin- } \\
\text { Watson }\end{array}$ \\
\hline 0.593 & 0.352 & 0.330 & 0.387 & 1.734 \\
\hline
\end{tabular}

As shown in Table 3, the adjusted R2 value is $0.330(\mathrm{~F}=16.080, \mathrm{p}<0.000)$, indicating that there is a strong association between course design, after-service, and expectation confirmation. In the multicollinearity test, the VIF values were all less than 10, indicating that there was no collinearity problem. The Durbin-Watson value is approximately 2, indicating that there is no possibility of autocorrelation between variables [36]. In addition, the internal model fits well. Table 4 presents the results of the regression analysis of the internal model. Among them, several variables, including professionalism, difficulty, and practicality of the course design and one-to-one tutoring, community discussions, and examinations in the afterservices and low initiative in the negative emotion, exhibited significant correlations. The pvalues for the course diversity, AI partners, unable to communicate, and unable to reach the goal exceeded 0.05, and there was no effect relationship with the dependent variable expectation confirmation.

Table 4. Regression Coefficient Analysis

\begin{tabular}{cllllll}
\hline \multicolumn{1}{c}{ Variable content } & \multicolumn{2}{c}{$\begin{array}{c}\text { Standardized } \\
\text { Coefficients }\end{array}$} & $\boldsymbol{t}$ & $\boldsymbol{p}$-value & $\mathbf{9 5 \%}$ CI & VIF \\
\hline ES & Expectation confirmation & - & -1.405 & 0.161 & $-0.565-0.101$ & - \\
CD1 & Professionalism & 0.343 & 5.116 & $0.000^{* * *}$ & $0.058-0.142$ & 1.271 \\
CD2 & Difficulty & 0.413 & 4.150 & $0.000^{* * *}$ & $0.049-0.133$ & 1.191 \\
CD3 & Diversity & 0.027 & 0.365 & 0.715 & $-0.022-0.071$ & 1.026 \\
CD4 & Practicality & 0.327 & 2.771 & $0.006 * *$ & $0.017-0.123$ & 1.177 \\
AS1 & One-on-one tutoring & 0.187 & 2.738 & $0.006 * *$ & $0.011-0.127$ & 1.069 \\
AS2 & Community discussion & 0.191 & 4.897 & $0.000^{* * *}$ & $0.019-0.137$ & 1.072 \\
AS3 & AI partners & -0.006 & -0.586 & 0.558 & $-0.033-0.049$ & 1.054 \\
AS4 & Exam & 0.125 & 5.141 & $0.000^{* * *}$ & $0.003-0.117$ & 1.042 \\
NE1 & Unable to communicate & 0.084 & 1.865 & 0.063 & $0.004-0.168$ & 1.226 \\
NE2 & Unable to reach the goal & 0.065 & 0.591 & 0.555 & $0.003-0.138$ & 1.139 \\
NE3 & Low initiative & 0.077 & 2.406 & $0.017 *$ & $0.015-0.145$ & 1.361 \\
\hline${ }_{0}<0.05 * *$ & $p<0.01 * * * p<0.001$ & & & & &
\end{tabular}

\subsection{Structural Equation Model Analysis}

Owing to the presence of mediator variables in the constructed theoretical model, SEM was used for validation to derive the overall model interactions. The degree of variation between the sample and fitted covariance matrix can be effectively assessed by testing the fitting degree in the SEM via the chi-square test [37]. The fitting degree can be judged by indicators, such as the goodness of fit index (GFI), adjusted goodness of fit index (AGFI), normed fit index (NFI), and comparative fit index (CFI), and is usually considered excellent when it exceeds 0.90 [38]. The two indicators of root mean square error of approximation (RMSEA) and standardized root mean square residual (SRMR), considering the model's parsimony, should 
be less than 0.10 [38]. Table 5 lists the indicators of the model fitting. All indicators meet the requirements, and the constructed SEM model has an appropriate fitting degree and descriptiveness.

Table 5. SEM fitting test

\begin{tabular}{ccccccc}
\hline Index & GFI & AGFI & NFI & CFI & RMSEA & SRMR \\
\hline Evaluation criterion & $>0.90$ & $>0.90$ & $>0.90$ & $>0.90$ & $<0.10$ & $<0.10$ \\
Fitting value & 0.972 & 0.921 & 0.989 & 0.972 & 0.059 & 0.018 \\
Model fitness & Accepted & Accepted & Accepted & Accepted & Accepted & Accepted \\
\hline
\end{tabular}

SEM models were constructed using AMOS 24.0, for the 385 valid samples collected, and the results of the analysis are shown in Table 6. By analyzing the path coefficients and pvalues, it can be determined that the path coefficient between DI and CB is 0.260 , with $t=$ 3.615 and $\mathrm{p}<0.001$, indicating that the domain image has a significant positive impact on continued use behavior. Therefore, $\mathrm{H} 1$ is valid. The path coefficient between $\mathrm{CD}$ and EC was 0.323 , with $\mathrm{t}=4.138$ and $\mathrm{p}<0.001$, indicating that course design has a significant positive impact on expectation confirmation. Therefore, $\mathrm{H} 2$ is valid. The path coefficient between AS and EC is 0.361 , with $\mathrm{t}=4.373$ and $\mathrm{p}<0.001$, indicating that after-service will have a significant positive impact on expectation confirmation. Therefore, $\mathrm{H} 3$ is also valid. The path coefficient between NE and EC was 0.031, with $\mathrm{t}=1.530$ and $\mathrm{p}=0.127>0.05$, indicating that there was no significant impact between negative emotion and expectation confirmation. Therefore, H4a is not valid. The path coefficient between NE and CB is -0.297 , with $t=3.987$ and $\mathrm{p}<0.001$, indicating that negative emotion will have a significant negative impact on continued usage behavior. Therefore, $\mathrm{H} 4 \mathrm{~b}$ is valid. The path coefficient between EC and CB is 0.349 , with $\mathrm{t}=4.450$ and $\mathrm{p}<0.001$, indicating that expectation confirmation will have a significant positive impact on the willingness to continue use. Therefore, $\mathrm{H} 5$ is valid.

Table 6. Path analysis

\begin{tabular}{ccccccc}
\hline Hypothesis & Path & Std. & S.E. & $\boldsymbol{t}$ & $\boldsymbol{p}$-value & Supported or not \\
\hline H1 & $\mathrm{DI} \rightarrow \mathrm{CB}$ & 0.260 & 0.039 & 3.615 & $0.000^{* * *}$ & Supported \\
H2 & $\mathrm{CD} \rightarrow \mathrm{EC}$ & 0.323 & 0.042 & 4.138 & $0.000^{* * *}$ & Supported \\
H3 & $\mathrm{AS} \rightarrow \mathrm{EC}$ & 0.361 & 0.037 & 4.373 & $0.000^{* * *}$ & Supported \\
H4a & $\mathrm{NE} \rightarrow \mathrm{EC}$ & 0.031 & 0.041 & 1.530 & 0.127 & Not supported \\
H4b & $\mathrm{NE} \rightarrow \mathrm{CB}$ & -0.297 & 0.040 & 3.987 & $0.000^{* * *}$ & Supported \\
H5 & $\mathrm{EC} \rightarrow \mathrm{CB}$ & 0.349 & 0.032 & 4.450 & $0.000^{* * *}$ & Supported \\
\hline
\end{tabular}

\section{Discussion and Suggestions}

In previous online education studies [13,14], most theories were based on the MOOC platform. In recent years, the B2B2C platform, excelling in the e-commerce sector, has also been proven to be applicable to online education [39]. However, the particularity of art education makes it difficult to apply the operation models in studies, most of which are black-box models based on theories. According to behavioral research on the B2B2C platform, there are three active decisions when customers use the platform [17]. This research, from the perspective of art 
education institutions, proposes auxiliary measures for every decision point. Empirical analysis shows that the course design and after-service of the product owner have a significant positive impact on the expectation confirmation of customers, which affects two important decisions in the trial stage and use (service) stage. Negative emotions exist in the entire use process, whereas the data shows that this variable skips the mediator (expectation confirmation), and has a direct and significant impact on the willingness to continue use. Hence, a method to alleviate the negative emotions of customers in practice must be developed [27].

To provide a more specific operational guideline, this study conducted further regression analysis of the factors affecting the mediator. The results show that professionalism and difficulty are essential items in art course design $(\mathrm{p}<0.001)$. Art education institutions should develop advantages in the specific field and increase competitiveness based on company features, such as presenting awards received in the specific field at the early stage of the course, designing more detailed special courses, and hiring famous external instructors. Easy-to-learn courses can bring a sense of accomplishment in students and contribute to improving their learning motivation. An appropriate sense of accomplishment serves as an incentive for longterm learning [40]. The practicality of the course also exerted a relatively significant influence $(p<0.01)$. Diversity is a common variable in the research of ordinary online education platforms [23,24]; however, it was not significant in this study from the perspective of art education.

The after-service factor is combined with the opinions of Chow and Shi [41] on online teaching platform behavioral research, with the AI partner as an external variable. One-to-one tutoring ( $p<0.01)$, community communication ( $\mathrm{p}<0.001)$, and regular assessments $(\mathrm{p}<0.001)$ were all significant. Additionally, the platform owner is responsible for offering tutoring and communication medium. Real-time video software, such as ZOOM, can be implemented to improve customer experience and expectation confirmation, in conjunction with the product owner, to achieve mutual benefits. The advantage of an online education platform is that it is important to have two-way communication rather than one-way communication. Based on pure video courses, teachers can be allowed to call AI modules to correct students' errors during the course, and assistance can be provided to students to complete the independent exercises after class. AI technology, though integrated into our lives, has not been supported by regression analysis. That is, the AI partner did not produce relevant relationships in the research. This is likely because the duration of the AI partner in the market is relatively short and is yet to be popularized. Ordinary art learners did not believe that AI partners can play a very good auxiliary role.

The questionnaire also collected respondents' negative opinions about online learning. Most of the users who were anxious about failure to conduct real-time communication had no experience in online learning. In addition, users who had experience in online learning, were concerned about poor learning initiatives and failure to achieve their expected goals. According to the results of the testing, customers' willingness to continue use was directly affected by such negative emotions. Therefore, in the overall model operation, attention should be paid to improving service, increasing communication, and understanding the real-time status of customers to avoid unnecessary customer loss. The questionnaire showed that $72.3 \%$ of respondents were willing to accept higher learning costs. Therefore, when the B2B2C platform is used to complete the operation, from the perspective of the marketing strategy of the product owner, demo courses and fee-based courses must be set up reasonably. Moreover, the launch of membership services can be a viable marketing program. 


\section{Conclusions}

The purpose of this research is to provide instructive theoretical models for art education institutions especially, music education academies. Owing to information technology, the world has become closer among people and more enterprises are likely to develop on a global scale. Traditional art education cannot be immutable, and a reasonable transformation should be conducted at the appropriate time. When unpredictable risks, such as pandemics, occur again, there will be more possibilities for contingencies. Therefore, this study has the meaning of timeliness and follow-through.

Based on the research of customer behavior on the B2B2C platform and using both the TAM and ECM theories, this study proposes an operation model suitable for art education institutions. The students from 15 art education institutions were investigated, and 385 valid samples were obtained. After constructing the research model, a regression analysis was performed on the influencing factors of the mediators, and the overall framework of the SEM was constructed. The proposed hypotheses were verified using the path coefficients.

Accordingly, domain image, course arrangement, and after-service affect the customers' three active decisions in the learning process of the B2B2C platform. Art education institutions, which play the role of the product owner, should pay attention to professionalism, difficulty, and practicality of the courses rather than diversity. At the end of the course, one-to-one tutoring, a learning community, and regular examinations are all effective techniques to raise customers' expectation confirmation. As the primary development direction of the information era, AI technology, which has not gained much attention from learners in the field of art education, is worth paying attention to. Furthermore, negative emotions do not influence expectation confirmation, but directly affect customers' final intention of continued use.

This research contributes to the academic area, specifically the ISs and practical sector acting as an art education platform. First, for an academic area, the proposed and enhanced B2B2C model based on art education includes verified theories and three important decisionmaking processes. For this model, we conducted empirical tests and found useful constructs and paths-as previously presented. Second, an art education institution, as the content owner, and online site provider, as the platform owner, can utilize this study's significant variables and paths on the expectation confirmation and the customers' willingness to continued use (continuance behavior). In particular, the higher proportion of online art education under contingent situations pushes stakeholders to reflect on the items required to continue business.

However, this study poses some limitations. It employed slightly subjective data obtained from a questionnaire survey. In future research, data mining should be conducted on the objective data including semi-/un- structured data generated by the online education platform to obtain more targeted analysis results. In addition, because the sample was collected from 15 Chinese art education institutions, an expansion or application of the findings to other countries' art education areas could have a generalizability problem. We expect a further study based on this study's model for various samples and countries.

\section{Acknowledgement}

We would like to thank Editage (www.editage.co.kr) for English language editing. 


\section{References}

[1] C. Nai, "Data analysis of the industry concerning online education,” China, Dec. 15, 2020. [Online]. Available: https://www.iimedia.cn/c1061/75791.html

[2] K. Y. Kim and I. K. Song, "Exploring working group’s psychological subjectivity on public smart work services in a cloud-based social networking," KSII Transactions on Internet and Information Systems, vol. 14, no. 12, pp. 4748-4762, Dec. 2020. Article (CrossRef Link)

[3] China Musical Instrument Association, "The impact of the COVID-19 epidemic on the musical instrument industry and policy recommendations,” China, Mar. 5. 2020. [Online]. Available: http://www.clii.com.cn/zhuantixinwen/fkyq/202003/t20200305_3942625.html

[4] Y. M. Zhao, A. F. Wang, and Y. Q. Sun, "Technological environment, virtual experience, and MOOC continuance: A stimulus-organism-response perspective," Computers \& Education, vol. 144, Jan. 2020. Article (CrossRef Link)

[5] K. M. Alraimi, H. Zo, and A. P. Ciganek, "Understanding the MOOCs continuance: The role of openness and reputation,” Computers \& Education, vol. 80, pp. 28-38, Jan. 2015.

Article (CrossRef Link)

[6] F. Davis, "Perceived usefulness, perceived ease of use, and user acceptance of information technology,” MIS Quarterly, vol. 13, no. 3, pp. 319-340, Sep. 1989. Article (CrossRef Link)

[7] N. On, G. Ryu, M. Koh, J. R. Lee, and N. Kim, "An empirical study on the intention to reuse computational science and engineering platforms: A case study of EDISON," KSII Transactions on Internet and Information Systems, vol. 14, no. 8, pp. 3437-3456, Aug. 2020. Article (CrossRef Link)

[8] A. Adwan, A. A. Adwan, and J. Smedley, "Exploring students acceptance of e-learning using Technology acceptance model in Jordanian universities," Education \& Development Using Information \& Communication Technology, vol. 9, no. 2, pp. 4-18, Aug. 2013. Article (CrossRef Link)

[9] R. A. Sánchez, A. D. Hueros, and M. G. Ordaz, "E-learning and the University of Huelva: A study of Web CT and the Technological acceptance model," Campus-Wide Information Systems, vol. 30, no. 2, pp. 135-160, Mar. 2013. Article (CrossRef Link)

[10] H. Apostolidis, T. Tsiatsos, P. Balaouras, and M. Gatzonis, "Evaluation of Open Delos online video editing and publishing platform for Greek open courses and MOOCs," in Proc. of IMCL, Thessaloniki, Greece, pp. 411-415, Nov. 2015. Article (CrossRef Link)

[11] L. R. Oliver, "A cognitive model of the antecedents and consequences of satisfaction decisions," Marketing Research, vol. 17, no. 4, pp. 460-469, Nov. 1980. Article (CrossRef Link)

[12] M. C. Lee, "Explaining and predicting users' continuance intention toward e-learning: An extension of the Expectation-confirmation model," Computer \& Education, vol. 54, no. 2, pp. 506516, Feb. 2010. Article (CrossRef Link)

[13] J. Groen, S. Ghani, A. Germain-Rutherford, and M. Taylor, "Institutional adoption of blended learning: Analysis of an initiative in action," Canadian Journal for the Scholarship of Teaching and Learning, vol. 11, no. 3, pp. 12-21, Dec. 2020. Article (CrossRef Link)

[14] Haitian E-commerce Financial Research Center, A book to understand online education, Univ. Tsinghua Press, Beijing, China, 2016.

[15] M. Mingione and L. Leoni, "Blurring B2C and B2B boundaries: Corporate brand value co-creation in B2B2C markets," Marketing Management, vol. 36, no. 1-2, pp. 72-99, 2020.

Article (CrossRef Link)

[16] E-commerce Research Group, "An analysis of the development experiences and status quo of electronic commerce in China,” The e-Business Studies, vol. 1, no. 1, pp. 137-149. Dec. 2007. Article (CrossRef Link)

[17] Q. Y. He, "Research on users' sustainable use behavior and influencing factors of B2B2C online education platform,” M.S. thesis, Jilin, Univ. of Jilin, Jilin, China, 2019.

[18] X. Z. Yang, Five-dimensional breakthrough: Internet + education, Electronic Industry Press, China, 2016. 
[19] F. X. Han, "Research on the evolution and innovation of regional musical instrument industry under the background of industrial integration,” Musical Instruments, vol. 4, pp. 90-93, 2021. Article (CrossRef Link)

[20] A. Bhattacherjee, J. Perols, and C. Sanford, "Information technology continuance: A theoretic extension and empirical test,” Computer Information Systems, vol. 49, no. 1, pp. 17-26, Dec. 2008. Article (CrossRef Link)

[21] X. J. An, Y. Liu, and L. Qi, "Research on the business model of science and technology service platform of creative industry under "Internet+" environment--an analysis for four typical creative fields," Science and Industry, vol. 21, no. 3, pp. 98-103, 2021. Article (CrossRef Link)

[22] C. L. Hsu, and J. C. C. Lin, "What drives purchase intention for paid mobile apps? An Expectation confirmation model with perceived value,” Electronic Commerce Research and Applications, vol. 14, pp. 46-57, 2015. Article (CrossRef Link)

[23] B. Xu, "The status quo and thinking of my country's basic music education under the value orientation of core literacy,” Art ocean, vol. 7, pp. 112-113, 2019. Article (CrossRef Link)

[24] E. Fianu, C. Blewett, A. Ampong, and K. S. Ofori, "Factors affecting MOOC usage by students in selected Ghanaian Universities,” Education Sciences, vol. 8, no. 2, pp. 70, May. 2018. Article (CrossRef Link)

[25] C. C. Wu, "2019 Internet music education industry insight report," China, 2019. [Online]. Available: https://www.douban.com/note/747110115

[26] H. Y. Wang, "How to define the professionalism of public art?,” Art Criticism and Theory, vol. 5, pp. 51-55, 2018. Article (CrossRef Link)

[27] C. H. Lin and Z. F. Liu, "A pilot study of Taiwan elementary school students learning motivation and strategies in robotics learning,” Edutainment Technologies, vol. 6, pp. 445-449, Sep. 2011. Article (CrossRef Link)

[28] Ai Media Consulting, “2018 China online education industry white paper,” China, 2018. [Online]. Available: https://www.iimedia.cn/c400/63080.html

[29] A. Bhattacherjee, "Understanding information systems continuance: An Expectation-confirmation model,” MIS Quarterly, vol. 25, no. 3, pp. 351-370, Sep. 2001. Article (CrossRef Link)

[30] A. K. Dalal and R. Singh, “An integration theoretical analysis of expected job attractiveness and satisfaction,” International Journal of Psychology, vol. 21, no. 1-4, pp. 555-565, May. 1986. Article (CrossRef Link)

[31] Y. Qian, "Research on the influencing factors of online learning users' continuous use behaviorbased on the perspective of social network environment and learning orientation," Modern Intelligence, vol. 3, pp. 50-56, 2015. Article (CrossRef Link)

[32] R. Eisinga, M. te Grotenhuis and B. Pelzer, "The reliability of a two-item scale: Pearson, Cronbach, or Spearman-Brown?,” International Journal of Public Health, vol. 58, no. 4, pp. 637-642, 2013. Article (CrossRef Link)

[33] J. Hauke and T. Kossowski, "Comparison of values of Pearson's and Spearman's correlation coefficients on the same sets of data,” Quaestiones Geographicae, vol. 30, no. 2, pp. 87-93, 2011. Article (CrossRef Link)

[34] R. H. Gim Chung, B. S. Kim, and J. M. Abreu, “Asian American multidimensional acculturation scale: development, factor analysis, reliability, and validity,” Cultural Diversity \& Ethnic Minority Psychology, vol. 10, no. 1, pp. 66-80, 2004. Article (CrossRef Link)

[35] D. Straub, M. C. Boudreau, and D. Gefen, "Validation guidelines for IS positivist research," Communications of the Association for Information Systems, vol. 13, pp. 380-427, Sep. 2004. Article (CrossRef Link)

[36] J. F. Hair, W. C. Black, B. J. Babin, R. E. Anderson, and R. L. Tatham, Multivariate data analysis, New York, NY, USA: Prentice-Hall International, 2006.

[37] T. D. Smith and B. F. McMillan, "A primer of model fit indices in structural equation modeling," Annual Meeting of the Southwest Educational Research Association, New Orleans, LA, USA, Feb. $1-3,2001$. 
[38] K. Bollen and J. Long, Testing structural equation models, Newbury Park, CA, USA: Sage Publications, 1993.

[39] D. S. Zhao, "Palm 1 on 1 gets C+ round of financing, sticks to B2B2C model," Entrepreneurship, vol. 8, pp. 106-107, 2017. Article (CrossRef Link)

[40] H. Hasan and R. Riswanti, et al., "Motivation and learning strategies: student motivation affects student learning strategies,” European Journal of Educational Research, vol. 10, no. 1, pp. 39-49, 2020. Article (CrossRef Link)

[41] W. S. Chow and S. Shi, "Investigating students' satisfaction and continuance intention toward elearning: An extension of the Expectation-confirmation model,” Procedia-Social and Behavioral Sciences, vol. 141, pp. 1145-1149, Aug. 2014. Article (CrossRef Link)

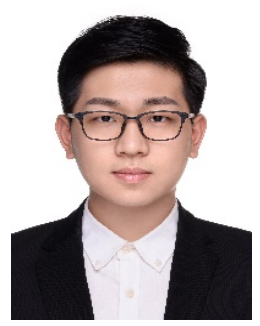

Shaopeng Hou is a candidate doctor at the Department of Information Systems in Hanyang University. He received the B.S. degree in Communication Engineering at Dalian University of Science and Technology and his M.S. degree in Information Systems from Hanyang University. He has great interest in Users’ Behaviors and Risk management.

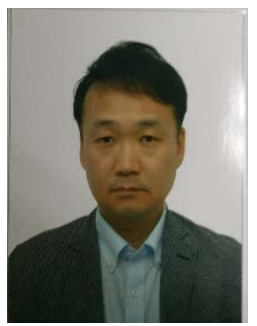

Jongchang Ahn is currently professor at the Department of Information Systems in Hanyang University. He received his B.S. degree in Economics at Korea University and his M.S. degree in Software Engineering from Sejong University. He received his Ph. D. in Information Technology Management from Hanyang University. He has great interest in Social Media \& Mass Media, IT Users' Behaviors, Electronic Commerce, and Knowledge Management. 